Available online at www.jmle.org

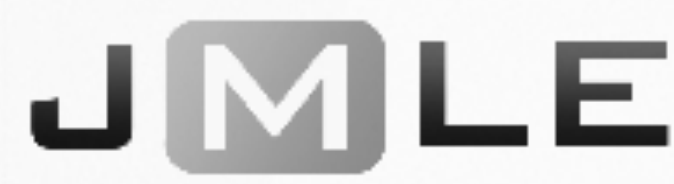

The National Association for Media Literacy Education's Journal of Media Literacy Education 10 (3), 113 - 131

\title{
Deconstructing Media in the College Classroom: A Longitudinal Critical Media Literacy Intervention
}

\author{
Andrea M. Bergstrom \\ Coastal Carolina University \\ Mark Flynn \\ Emmanuel College \\ Clay Craig \\ Texas State University - San Marcos
}

\begin{abstract}
While many studies have addressed the impact of media literacy interventions on knowledge of specific topic areas, fewer have explored improvements in media literacy skills as outcome measures. This study analyzed the impact of a media literacy intervention on participants' critical thinking skills and understanding of media literacy principles by addressing the topics of body image and media representations of gender and race. A two-group, longitudinal experimental design was implemented using college-aged student participants across multiple introductory communication course sections $(n=198)$ at a public university in the southeast. Results were significant for several media literacy measures for the treatment group after exposure to the intervention compared to the control group. These findings were persistent over the duration of the semester as demonstrated in the second posttest.
\end{abstract}

Keywords: critical media literacy, longitudinal, intervention, gender, race, body image

While historically the term literacy has referred to the ability to read and write, in modern society most information is distributed through a variety of communication technologies, making the ability to "read" and understand a range of mediated formats an essential skill to successfully navigate today's culture (Center for Media Literacy 2016). As Wood (2011) pinpointed, "People today are the most media-saturated and media-engaged people in history" (256). Relatedly, as noted by Kellner and Share (2005), it would be irresponsible for educators to ignore the complexities of the media landscape with which students today engage. 
As students are spending more time with media, faculty have noted the lack of preparedness of students entering higher education, and their tendency to be limited in their media literacy skills beyond the ability to simply access content (Schmidt 2012). However, the incorporation and assessment of media literacy skills training into college classrooms has received only limited scholarly attention (Scharrer 2007). Scholars have called for greater attention and prioritization of media literacy in primary schooling as well as higher education curricula to address existing gaps in this knowledge area (Kellner and Share 2005; Thoman and Jolls 2004). The research at hand works toward addressing this call by incorporating a critical approach to teaching media literacy at the collegiate level as well as by testing measures through which achievements in media literacy skills can be examined.

Additionally, media literacy education has been cited as instrumental in minimizing potential negative effects on audiences who are exposed to unrealistic media content and this may have a positive impact on self-perceptions. A protectionist approach to media literacy includes research on the effects of media exposure on adolescents and young adults with findings that media consumption can lead to unrealistic perceptions of the body ideal (Irving and Berel 2001; Lavin and Cash 2000; Levine and Harrison 2009), gender roles (Craig 1997; Mathews 2007), and race (Frisby 2004; Gilliam and Iyengar, 2000; Hurley, Jensen, Weaver and Dixon 2015), among other areas. Other scholars envision the teaching of media literacy as a tool of empowerment for students to find and evaluate information and engage as active audiences to think critically about media and technology (Cole, Biel, Pai and Chand 2007; Hobbs 2011). Across perspectives researchers have consistently pointed to media education as a potential strategy for student engagement with varied media content and increase critical thinking, but specific gains in these areas from media literacy interventions need to be considered considered further (Hobbes 2011).

Interestingly, while scholars refer to the importance of media literacy interventions, there is comparatively less published literature on successful interventions (Arke and Primack 2009; Bergsma and Carney 2008, Garcia, Seglem and Share 2013). The need for additional research attention was a primary reason for the current intervention. A second rationale for this analysis was the lack of focus on the acquisition of specific media literacy skills in interventions (Arke and Primack 2009). Interventions to date tend to focus on gains in knowledge and attitudes in specific content area outcomes, such as changes in body image measures (Irving and Berel 2001; Lavin and Cash 2000; Levine and Harrison 2009). However, a focus on advances in participants' media literacy knowledge and skills is less commonly addressed in reported outcomes. Finally, the study at hand specifically investigates the teaching of media literacy content within an introductory communication course, a place that scholars have consistently noted as a fruitful starting point for the inclusion of media literacy outcomes within communication curricula (Cramer 2015; Masterman 1985).

For media literacy interventions focused on topics such as body image, it seems that gains in thinking critically about media are often an assumed step between exposure to media education initiatives and measured changes perceptions. Measures specifically examining changes in media literacy are not commonly reported. The current analysis examines this important, yet frequently neglected, component of media 
literacy interventions. Finally, another consistent shortcoming in the results of media literacy interventions to date is the lack of longitudinal data. Research has largely focused on the immediate impact of media literacy interventions and has failed to assess for any effects lasting over a prolonged period of time (Austin, Pinkleton, Chen and Austin 2015; Ridolfi and Vander Wal 2008; Yager and O'dea 2008). Therefore, this analysis will also assess any lasting changes in media literacy skills that persist at a follow-up delayed second post-test distributed at the end of the course, approximately one month after the intervention.

\section{LITERATURE REVIEW}

In response to today's media-saturated landscape and increasing awareness of the need for media education, many scholars, educators and practitioners have designed and facilitated a range of curricular interventions as a means to address this perceived deficit in media literacy skills. Such interventions have examined a range of topics and media content and have been targeted toward varied populations and age cohorts. When initially embarked upon by communication scholars, media literacy was intended to address participants' abilities to access, analyze, evaluate and produce media in a variety of forms (Aufderheide 2001).

However, while these desired outcomes still hold true, recent shifts in media literacy endeavors have moved toward addressing the vast media presence more comprehensively as well as attending to perceived educational needs within the $21^{\text {st }}$ century. Kellner and Share (2005) have expressed the importance of addressing the scope of media literacy in today's ubiquitous multimedia environment. In this regard, approaches to media literacy have expanded to encompass an understanding of the role of media in society as well as the essential skills of inquiry and critical thinking necessary to foster the development of empowered and engaged citizens (Center for Media Literacy 2016).

As noted by Hobbs (2001), at its core, media education is about viewers asking questions about the media watched, seen and read. Beyond analysis of media texts, Masterman (2001) proposed that media education should aim to empower students to become critical and autonomous thinkers. Media literacy can ideally serve to deepen students' understanding of media content as well as contextualize the social, economic and historical conditions in which media messages are created and circulated (Hobbs 2011). While scholars and educators may approach media literacy from seemingly diverse theoretical and methodological perspectives, common outcomes are often intended, as most media education frameworks focus on the enhancement of critical thinking skills within their desired objectives and encourage active engagement by audiences with the media content they encounter (Scharrer 2007).

According to the key tenets of media literacy, it is crucial to understand that all media are constructed and construct perceptions of reality, media have commercial as well as ideological and political implications, form and content are intertwined within each medium, each of which has a particular aesthetic and accepted conventions, and that audiences negotiate meaning from media messages (Aufderheide, 2001). In this sense, media literacy encourages greater awareness of the overall media landscape and 
the necessary skills to advocate for systemic change (Cramer 2015). To expand upon these tenets and employ a critical media literacy framework is to foster an understanding of media with an awareness of the social, political, and economic contexts in which such texts are produced and disseminated. According to Kellner and Share (2005),

Critical media literacy involves cultivating skills in analyzing media codes and conventions, abilities to criticize stereotypes, dominant values, and ideologies, and competencies to interpret the multiple meanings and messages generated by media texts (372).

Expanding on this conception of media literacy, Garcia, Seglem, and Share (2013) utilize a critical approach in their work with high school and college-aged students by expanding their definition of literacy to incorporate various forms of mass communication, popular culture, and new technologies in order to critically examine the relationship between media messages, audiences and ideologies. Across definitions and perspectives, fostering critical thinking skills and encouraging analytical engagement with media pervade as commonly articulated goals of media literacy implementation and remain central to the research at hand. The current study encourages critical engagement with a variety of media texts and formats in regard to their representations of gender, race and body image as well as consideration of the economic and ideological components embedded within the production and reception of these messages.

\section{Media Literacy Interventions}

Specific media literacy interventions have been developed by scholars and educators in an effort to address varied media portrayals and increase media literacy. A meta-analysis of media literacy interventions by Jeong, Cho and Hwang (2012) demonstrates that overall interventions are generally effective when teaching content and can be used to address the potential negative effects of media messages $(d=.37)$. Results of Jeong and colleagues' meta-analysis of media literacy interventions notes that active audience involvement through discussion or alternative activities was more effective overall than those interventions that included only passive listening because they require greater comprehension and additional mental effort. Additionally, interventions commonly focus on enhancing critical thinking skills and have greater success when teaching for media-related concepts, such as knowledge of media conventions and persuasion techniques, rather than the altering attitudes or behavioral outcomes among participants, such as self-efficacy (Jeong, Cho and Hwang 2012).

Notable examples of interventions have focused on gender and race representations within media messages, body image, and related health behaviors. Body image has been of particular interest to media literacy scholars due to the potential negative effects on consumers, such as poor body image, anxiety, disordered eating behaviors and eating disorders (The American Psychological Association 2007). In addition, Douglas (1995), Kilbourne (2003), and others have long since documented the concerning impact that media exposure has on girls' and young women's self-esteem. 
Media literacy programs that focus on adolescent girls have demonstrated positive outcomes, with these efforts impacting how girls perceive themselves, their bodies, and other girls. Media education interventions designed to promote awareness of the ways in which gender norms, stereotypes and sexualization impacts girls and young women have been shown to be an effective way to mitigate the pervasive influence of media and to encourage critical thinking (Bindig 2009; Bullen 2009). Limited research has examined changes in participants' self-perceptions following gender and body image centered media literacy interventions (Irving and Berel 2001).

In regard to the body image interventions using media literacy, while measures have been used to assess related outcomes (e.g. body satisfaction, disordered eating behavior), less research attention has been given to changes in fundamental areas of media literacy and the enhancement of related concepts (Watson and Vaugh 2006). However, one study found that a body image intervention was successful at fostering a sense of media skepticism, considered to be a key aspect of media literacy (Irving and Berel 2001). In light of this successful outcome, the current analysis will also use the topic of body image and consider media representations of gender and race as a platform for this intervention to enhance participants' media literacy skills.

Based on the potential for increased media literacy skills as a result of the media literacy intervention, the following hypotheses were created.

H1: Participants exposed to the media literacy intervention will increase their media literacy significantly more than the control group.

H2: Participants exposed to media literacy intervention will increase their understanding of the inaccurate media portrayals of women and men significantly more than the control group.

In an early example of a media literacy initiative, Rabak-Wagener and colleagues (1998) exposed male and female college students $(\mathrm{N}=105)$ to an intervention spanning four class sessions which included viewing Kilbourne's documentary Slim Hopes and participation in follow-up discussions of female gender stereotypes and the thin ideal promoted by the media. Findings showed that women who participated in the intervention and were exposed to the curricular materials had a statistically significant improvement in their overall perceptions of body image when compared to women in the control group. No significant differences were found between men in the experimental condition compared to the control group (RabakWagener, Eickhoff-Shemek and Kelly-Vance 1998). While their study demonstrated gender differences do exist based on body image outcomes, scant research has examined gender as a potentially important variable in the development of media literacy skills. Therefore, the following research question was developed to assess potential differences based on gender.

RQ1: In the media literacy intervention group, are there significant differences based on participants' gender? 
Fewer media literacy interventions have tackled race and racial stereotypes directly, media literacy can also be employed as a strategy to engage in critical conversations regarding these issues. Media messages tend to depict minority groups in limited and inaccurate ways that impact viewers' attitudes (Hurley et al. 2015; Tukachinsky, Mastro and Yarchi 2015). Such media representations can be especially powerful for audiences who have had only limited real life multicultural experiences to combat media stereotypes (Owusu 2010). Using media literacy as a tool to engage in critical discussions of representations of gender, race and class across media such as television, film and advertising requires challenging stereotypes through which people of color are often portrayed in mainstream media messages (Kellner and Share 2005). Media literacy can provide an opportunity to engage critically with such inaccurate portrayals and the related beliefs about race that perpetuated through media (Aufderheide 2001).

Without the chance to deconstruct such representations through critical thinking and media literacy, media messages can powerfully influence perceptions of various minority groups. Thus, a third hypothesis was developed to address this potential effect. As few studies have employed and measured the effectiveness of media literacy as a strategy to address the limited and stereotypical portrayals of minority groups that pervade media content, this is a key area in which the present study intends to contribute. In addition, some research has shown that viewers' race/ethnicity may be an important consideration when addressing the impact of media representations of race (Hurley et al. 2015), yet limited research has considered race as a variable in the relationship between media literacy training and the acquisition of media literacy skills. Therefore, a final research question was also proposed to address this underexplored area.

H3: Participants exposed to the media literacy intervention will increase their understanding of the inaccurate media portrayals of race significantly more than the control group.

RQ2: In the media literacy intervention group, are there significant differences based on participants' race?

Additionally, many media literacy scholars and educators have long acknowledged the importance of evaluation and assessment in any media literacy intervention (Christ and Potter 1998, Scharrer 2007). The identification of specific measurable outcomes and assessment of the overall effectiveness of media literacy curricula are essential within the implementation of media literacy programs, yet educators have come to realize that assessing the effectiveness of any given media literacy program poses challenges.

Although research on the efficacy of media literacy has steadily grown in recent decades (Hobbs and Frost 2001; Irving and Berel 2001; Scharrer 2007), even resulting in a meta-analysis of intervention outcomes (Jeong, Cho and Hwang 2012), limited discussion exists regarding the measurable outcomes ideally associated with media literacy and its effectiveness over time. While this body of inquiry continues to expand 
the field in important ways, the overall assessment of media literacy remains an arena that can benefit from additional consideration.

Scant research exists to assesses lasting effects in media literacy interventions. In a meta-analysis of body image interventions (Yager and O'dea 2008), while none of the media literacy-based studies included follow up assessment, several studies included in the analysis did assess lasting effects as defined by a one-month follow-up (Becker et al. 2005; Green et al. 2005; Matusek et al. 2004; Stice et al., 2000). Also, one recent media literacy study assessed lasting effects six weeks after the initial intervention in grade school children (Byrne 2009). However, no longitudinal assessment of media literacy has been conducted that used a college sample. The study at hand contributes to the overall assessment of media literacy programs by examining specific measurable outcomes at different points in time as a means to demonstrate enhanced critical thinking about media representations by those students who were exposed to the media literacy curriculum compared to those who were not. Based on the potential for the media literacy skills to endure over time, a final hypothesis was created.

H4: The significant gains in media literacy for the intervention group will persist over time.

\section{METHODS}

The intervention at hand incorporates media literacy into a general education introductory communication course at a mid-sized public university in the southeast as a means to address representations within today's media landscape. This curriculum was informed by tenets of media literacy in the design of the materials for the intervention, focusing specifically on gender representations across television, film, magazines and advertisements with particular consideration of gendered body ideals, stereotypical racial representations and corporate media's profit motive through a critical lens.

Content was tailored to a higher education classroom setting, an audience with a demonstrated need for additional media literacy (Schmidt 2012). The intervention focused on fostering critical media literacy skills as defined by the Center for Media Literacy's definition (2016). This skill set includes four main objectives; being able to access media content, critically analyze media messages, evaluate media representations and to create alternative media (Thoman and Jolls 2015). Developing the ability to analyze and critically evaluate media content and context were explicitly addressed within the intervention.

This study employed a two-group (Condition: experimental or control), between groups (Time: baseline, intervention or post-intervention) experimental design. Both experiment and control conditions answered identical questionnaire items at three different points during the same semester. Participants were assigned to either the control or experimental group based on their course enrollment. All intervention group participants were enrolled in one of five sections of an introductory media and communication course. The media literacy intervention was well-suited for the content 
and nature of this course and responds to calls for introductory communication courses to include media literacy in their stated learning outcomes (Cramer 2015). To avoid the potential influence of themes that would be covered in this intervention, all participants placed into the control group were enrolled in courses outside the discipline that do not discuss media literacy as a course concept.

\section{Procedure}

First, all study participants were asked to complete a pre-test measurement of the variables of interest to establish a baseline. Approximately two weeks after the pretest was completed, participants in the intervention group received the media literacy intervention on the topics of body image and gendered and racial media representations. The intervention was approximately 65-75 minutes in duration for all intervention groups (30-35 minutes focus on portrayals of women; and 30-35 minutes focused on portrayals of men). For longer classes that met twice a week, one class period was sufficient to complete the intervention. In shorter classes that met three times a week, two consecutive class periods were used. In response, the curriculum was designed to engage students, posing questions to prompt engagement and participation.

The intervention involved comprehensive media literacy lessons on both male and female body image that included: an interactive discussion of media representations of the body ideal; how those representations are used in advertising, television, film and music in an attempt to increase profits; the difference between media representations and real US body types; an examination of gender and race differences in body image representations; the potential effects on audiences; and an overview of ways participants could get involved on campus or challenge the media portrayals in other ways. The intervention was created as an interactive PowerPoint presentation that included media literacy information, relevant images and examples and video content. Time for questions and discussion was also incorporated into each intervention session.

For all course sections that were included in the intervention, the same two experts, one female and one male, presented the material. The female expert presented the material focused on women and the male expert presented the material focused on men. The presenters' expertise was determined based on their previous research on gender, race and body image as well as their regular inclusion of these topics in their teaching.

The intervention was designed with the thought that instructors of introductory media and communication courses could effectively replicate the delivery of the intervention material. In fact, the authors designed this experiment knowing that many teaching such courses already do address aspects of the content included. The current study sought to quantitatively assess how effective such teaching can be for media literacy outcomes, and if there are any lasting effects. Immediately after the stimulus material was presented, participants in the intervention group completed the first posttest. For participants in the longer class period, the post-test was administered on the same day as the intervention and for participants in the shorter class period, the posttest was administered on the second day at the conclusion of the intervention. During the same week, participants in the control group classes also completed the post-test. 
Approximately four weeks after the initial post-test, all participants took another version of the post-test to assess any lasting impact of the intervention. This relative timeframe also enabled the implementation of the current experimental design and procedure to be completed in one semester.

\section{Measures}

Media literacy was assessed using Bindig's (2009) semantic differential items created for an ERA curriculum with the addition of one item. The ten items represent four of the core concepts of media literacy proposed by Aufderheide (2001). The items include: (ML1) Media's main goal is to: serve the public/make money, (ML2) Media have a: strong influence/no influence, (ML3) Media tend to: reflect reality accurately/distort reality, (ML4) TV impacts people: exactly the same way/potentially different ways, (ML5) The media: can easily be changed/is difficult to change, (ML6) Media usually: tell the whole story/doesn't tell the whole story, (ML7) Media: are just for fun/influence what people think about the world, (ML8) Members of minority racial groups are portrayed: fairly in the media/unfairly in the media, (ML9) Women are portrayed: accurately-realistically in media/inaccurately-unrealistically in media, and (ML10) Men are portrayed: accurately-realistically in media/inaccuratelyunrealistically in media. Participants recorded their responses on five-point semantic differentials.

\section{RESULTS}

The sample consisted of college students $(N=198)$ enrolled at a mid-sized public university in the southeast that participated in the experiment for extra-credit in one of several introductory communication and general education courses. Prior to data analysis studentized residuals were calculated for each media literacy variable. Cases with a studentized residual absolute value above 3 were excluded from analysis on a per variable basis.

The respondents were divided into the experimental group $(57.6 \%, n=114)$ and a control group $(42.4 \%, n=84)$. The participants were primarily female $(62.1 \%, n=$ $123)$ and the age of the participants ranged from 16-29 with a mean age of $19.89(S D=$ 1.59). The sample was predominantly Caucasian $(68.7 \%, n=136)$ followed by AfricanAmerican $(20.7 \%, n=41)$, Other $(6.1 \%, n=12)$, Hispanic $(1.5 \%, n=3)$ and Native American $(1.5 \%, n=3)$. This distribution reflects the student population at the university.

To ensure there was not a difference between the two conditions (experimental vs. control) a series of $t$-tests were conducted to compare baseline differences between the two conditions. Data revealed no difference between the two conditions for all media literacy variables.

The effects of the intervention were assessed through mixed ANOVAs for each media literacy variable. There was a statistically significant interaction between the intervention and the immediate post-test on media's distortion of reality (ML3), $F(2$, $376)=4.68, p<.05$, partial $\eta^{2}=.024$; media impacts people differently (ML4), $F(2$, $376)=4.18, p<.05$, partial $\eta^{2}=.022$; media tells the whole story (ML6), $F(2,388)=$ 
2.45, $p<.05$ (one-tailed), $\eta^{2}=.012$; media's representation of minorities (ML8), $F(2$, $376)=6.02, p<.001$, partial $\eta^{2}=.062$; media's representation of women (ML9), $F(2$, $378)=5.35, p<.01$, partial $\eta^{2}=.028$; and media's representation of men (ML10), $F(2$, $388)=7.43, p<.001$, partial $\eta^{2}=.037$. As Table 1 shows, additional one-way ANOVAs were conducted to assess the main effects of conditions for each variable at both immediate post-test and delayed post-test.

Hypothesis 1 pertained to overall media literacy differences between groups and was partially supported. Data revealed a significant main effect on media's distortion of reality (ML3) and media tells the whole story (ML6) in the immediate post-test. For both variables the experimental condition had significantly higher levels of media literacy than the control group (Table 1). Therefore, the first hypothesis was partially supported.

Hypothesis 2 was supported. Data analysis revealed significant differences between intervention and control groups in their perceptions of how media inaccurately portrays women (ML9), $\left(F(1,191)=7.97, p<.01, \eta^{2}=.04\right)$ and men (ML10), $(F(1$, $\left.195)=14.63, p<.001, \eta^{2}=.07\right)$ in the immediate post-test. Participants in the intervention condition viewed media's representation of men and women as more inaccurate than the control group.

Hypothesis 3 was also supported. A one-way ANOVA showed participants in the experimental group viewed media portrayals of minorities as significantly less accurate than participants in the control group in the immediate post-test (ML8), $F(1$, $190)=14.03, p<.001, \eta^{2}=.089$.

To test the fourth hypothesis a series of one-way ANOVAs were conducted to examine if there were significant differences between the two conditions at the delayed second post-test. Data revealed significant differences for media impacting people differently (ML4), $\left.F(1,192)=15.26, p<.001, \eta^{2}=.07\right)$, media tells the whole story (ML6), $\left.F(1,195)=7.24, p<.01, \eta^{2}=.036\right)$, media's representation of minorities $F(1$, $194)=8.27, p<.01, \eta^{2}=.041$, media's representation of women (ML9), $F(1,194)=$ $\left.7.29, p<.01, \eta^{2}=.036\right)$ and men $\left.(\mathrm{ML10}), F(1,194)=8.07, p<.01, \eta^{2}=.04\right)$.

Research question 1 pertained to the influence of gender on the media literacy intervention. Prior to data analysis the control group participants were excluded from consideration. When examining only the intervention condition, a series of mixed ANOVAs displayed statistically significant interactions between gender and the immediate post-test (ML2), $F(2,204)=2.68, p<.05$ (one-tailed), partial $\eta^{2}=.026$; $(\mathrm{ML} 3), F(2,210)=3.07, p<.05$, partial $\eta^{2}=. .028$; (ML4), $F(2,210)=3.76, p<.05$, partial $\eta^{2}=.035$; (ML5), $F(2,220)=2.70, p<.05$ (one-tailed), partial $\eta^{2}=.024$; media telling the whole story (ML6), $F(1.85,201.09)=4.40, p<.05$, partial $\eta^{2}=.039$. As Table 2 shows, one-way ANOVAs for each statistically significant interaction at both the immediate and the delayed post-tests were conducted to determine main effects.

Finally, the second research question assessed the influence of race on the media literacy intervention. To address this question, participants' race was first dichotomized into two categories: "White" and "Non-White". Examining racial differences in the experiment condition through mixed ANOVAs revealed a statistically significant interaction between race and immediate post-test (ML8), $F(2,208)=5.14, p$ $<.05$, partial $\eta^{2}=.047$. As Table 3 shows, an additional one-way ANOVA revealed 
significant differences between Whites $(M=4.12, S D=.97)$ and Non-Whites $(M=$ $4.53, S D=.70)$ at the delayed post-test $F(1,109)=5.07, p<.05$, partial $\eta^{2}=.044$.

\section{DISCUSSION}

Limited research has assessed the impact of interventions on participants' media literacy and critical thinking skills (Arke and Primack 2009; Bergsma and Carney 2008; Bindig 2009; Irving and Berel 2001). Rather, most media literacy interventions have focused on reducing negative outcomes related to the topic used (e.g. health factors, body image, etc.) Furthermore, the results of the meta-analysis conducted by Jeong, Cho and Hwang (2012) suggest that media literacy interventions across a variety of topics can be an effective in reducing the impact of media messages.

While scholars continue to conduct media literacy interventions and extend curricula into new topical areas, limited assessments exist that measure the impact of media literacy interventions over time. This study was designed to bridge these two specific shortcomings in the literature. Overall, the findings show promise for an intervention designed to increase the critical media literacy skills of the experimental group using the topics body image and gendered and racial media representations as a mode for developing media education and critical thinking among college-aged audiences. Furthermore, the implementation and assessment of this intervention may also provide insight and guidance for other scholars and educators who intend to incorporate media literacy content into their own introductory communication courses.

The first hypothesis received partial support in that the intervention group showed significant improvement on two of the seven general media literacy questions immediately following the intervention. Specifically, participants in the intervention group were more likely to develop an understanding that media images are commonly unrealistic and that media does not tell the whole story. These findings most closely support Irving and Berel's (2001) results that a body image media literacy campaign can help participants to develop an overall level of media skepticism. Additionally, while specific media literacy measures were not evaluated by Jeong, Cho and Hwang (2012), the results of the current study also lend additional support for their metaanalysis finding that participants in media literacy interventions often demonstrate a greater understanding of media conventions and distortions following their participation, a central aspect toward fostering critical thinking about mediated content.

The second and third hypotheses on gender- and race-based media literacy respectively, were fully supported. Participants in the intervention group showed an increased understanding at the immediate post-test that both women and men are inaccurately portrayed in media content. This experimental group was also significantly more likely to understand that minority groups are commonly misrepresented and stereotyped in media content. As noted by Kellner and Share (2005) and other advocates for a critical media literacy approach, media education interventions that address the injustices of gender, race and other inequalities and also challenge these inequities as they are depicted in media are essential in today's multicultural society. Empowerment through media literacy is essential for students to learn to think critically and to begin challenge the larger systems that produce media messages (Hobbs 2015). 
Providing a framework to critically analyze, deconstruct and challenge mainstream media representations of body image, gender and race was at the forefront of this media literacy invention. The support for these two hypothesizes demonstrates the current intervention was successful in this area.

The final hypothesis predicted that the impact of the intervention would persist over time and was partially supported. Participants in the intervention group scored significantly higher than those in the control group on five out of ten media literacy items on the second post-test, this follow-up which was administered one month after the intervention to examine the longitudinal impact. On two of the seven more general media literacy items, the intervention group reported significantly higher levels of media literacy. Specifically, participants in the intervention group were more likely than those in the control group to understand that media impacts people differently, and that media does not tell the whole story. These results also add evidence to the growing body of literature that encourages the incorporation media literacy content into introductory-level communication courses (Cramer 2015) and demonstrates one model for which media education can be effectively included.

In addition, all three items measuring gender and race remained significant for the intervention group over time as measured at the second delayed post-test, showing that the intervention had a strong and lasting impact on participants' understanding of these issues, in particular. These findings demonstrate support for increased understanding and critical thinking by those participants who experienced the media literacy intervention and engaged with the curricular materials designed for this study. This finding is particularly noteworthy in consideration of the lack of longitudinal data available from prior media literacy interventions (Yager and O'dea 2008). To date, no previous longitudinal media literacy data has been collected from a college-student sample. The retention of these critical media literacy components also lends support for the relevance of issues of body image, and media representations of gender and race in the lives of college-aged participants. These findings demonstrate areas of effective teaching and learning and the successful implementation of active engagement strategies within this critical media literacy intervention as a means to increase and retain media literacy skills among college students.

In addition, by looking at the participant level variables of gender and race, this study addressed a limitation in previous media literacy interventions (Bergsma and Carney 2008). Overall, women improved on one media literacy item at the immediate post-test and four items at the delayed follow-up post-test significantly more than men. Directly after the intervention, women were more likely than men to believe that it would be difficult to change the media, showing their understanding of the complexity of the media industry. Over time, women persisted in this belief, and also demonstrated a better understanding than men that: media tend to distort reality; media impacts viewers in potentially different ways; and that media do not always tell the whole story. At the second follow-up post-test, men were more likely than women to think that media have a strong influence. Interestingly, neither of the two items measuring gendered media representations were significant based on participants' own gender. Further exploration of these gender differences could prove beneficial in the creation 
and implementation of future media literacy curricular materials and interventions designed to target specific populations.

In a similar line of inquiry, the second research question investigated the potential differences in the media literacy outcomes by the race of the intervention participants. No significant results were observed after the initial post-test assessment. However, one month after the intervention, at the second follow-up post-test, NonWhite participants were significantly more likely than White participants to think that members of minority/racial groups are more likely to be portrayed unfairly. This finding supports the limited previous research that addressed variations in participants' ethnicity when looking at the impact of unrealistic media portrayals of ethnic minorities (Hurley et al. 2015) as well as the importance of collecting longitudinal data, as lasting intervention effects may vary across diverse participants over time. This finding also calls attention to the need for continued expansion of critical media literacy interventions as a means to foster additional understanding of the complexities of media portrayals and promote an understanding of social justice issues. Additional investigation into this difference in perceptions between Non-White and White participants of representations of race, ways to address this variation, and the delayed impact of the media literacy interventions is clearly warranted.

\section{Limitations}

This study has some limitations. While the experimental design employed here was useful to explore the impact of a media literacy intervention, generalizations of the findings must be applied with caution. Further research is necessary to support these findings in additional settings and/or contexts. However, it is noteworthy that some of the findings here lend support to the limited previous research that found increased levels of media skepticism resulting from a body-image focused media literacy intervention (Irving and Berel 2001), as increased awareness and understanding of aspects of media literacy and critical thinking were demonstrated within the results of the intervention at hand. Based on the environmental constraints, the design also failed to use random assignment of participants. While this is indeed a limitation, an assessment of variation between groups at the onset of the intervention found no significant differences between the experiment and control groups. Finally, the lasting effects were assessed four weeks after the media literacy intervention. Additional research that follows an intervention group beyond the duration of one semester may provide additional insight into the lasting impact of media literacy interventions.

\section{Future Research}

The gender- and race-based differences found here provide an interesting level of nuance for understanding the impact of media (Bergsma and Carney 2008). However, more inquiry into these potential differences would be necessary to draw more practical conclusions. In particular, it would be useful to discover preferred context of media literacy training to enhance the impact in both men and women on all outcome measures. For example, this intervention presented media literacy content that focused on representations of men and women, as well as different ethnic groups. Further examination into the ways media literacy interventions could potentially 
empower diverse participant groups may also be a fruitful area for future consideration. In addition, the two presenters themselves accounted for both genders, but were not representative of a minority group. Assessing the impact of variations in such aspects of media literacy intervention design and delivery may provide additional insight into this complex topic.

The results here show the promise for critical consideration of the topics of gendered and racial media representations as well as body image to serve as the vehicle to enhance general media literacy skills and critical thinking about mediated content within the context of a one-semester introductory college-level course. Also, those interested in implementing critical media literacy interventions would also benefit from the assessment of other topic areas as a means to develop general media literacy skills as well as topic-specific knowledge. Overall, the current study demonstrates significant gains for the college-aged intervention participants in their acquisition of critical media literacy skills compared to the control group that were retained over a period of time.

\section{REFERENCES}

Arke, Edward T., and Brian A. Primack. 2009. "Quantifying Media Literacy: Development, Reliability, and Validity of a New Measure." Educational Media International 46 (1):53-65. doi: 10.1080/09523980902780958.

Aufderheide, Patricia. 2001. "Media Literacy: From a Report on the National Leadership Conference on Media Literacy." In Media Literacy in the Information Age: Current Perspectives, edited by Robert Kubey, 79-88. New Brunswick, NJ: Transaction Publishers.

Austin, Erica W., Bruce E. Pinkleton, Yi-Chun Chen and Bruce W. Austin. 2015. "Processing of Sexual Media Messages Improves Due to Media Literacy Effects on Perceived Message Desirability" Mass Communication and Society 18: 399421.

Bergsma, Lynda J., and Mary E. Carney. 2008. "Effectiveness of Health-Promoting Media Literacy Education: A Systematic Review." Health Education Research 23 (3):522-542.

Bindig, Lori B. 2009. “A New 'Era': Media Literacy in Eating Disorder Treatment.” Unpublished doctoral dissertation.

Bullen, Rebecca Richards. 2009. "The Power and Impact of Gender-Specific Media Literacy." Youth Media Reporter 3:149-152.

Center for Media Literacy. <www.medialit.org > accessed 3/12/16

Christ, William G., and W. James Potter. 1998. "Media literacy, Media Education, and the Academy." Journal of Communication 48 (1):5.

Cramer, Linsay M. 2015. "Teaching the Foundations of Media Literacy in the Basic Communication Course." The Forensic of Pi Kappa Delta 100: 13-32.

Douglas, Susan. 1995. Where the Girls Are: Growing Up Female with the Mass Media. New York, NY: Random House.

Frisby, Cynthia M. 2004. "Does Race Matter? Effects of Idealized Images on African American Women's Perceptions of Body Esteem." Journal of Black Studies: Sage Publications, Inc. 323-347. 
Garcia, Antero, Robyn Seglem, and Jeff Share. 2013. "Transforming Teaching and Learning Through Critical Media Literacy Pedagogy." LEARNing Landscapes 6 (2) 109- 124.

Gilliam, Franklin D., and Shanto Iyengar. 2000. "Prime suspects: The Influence of Local Television News on the Viewing Public." American Journal of Political Science 44; 560-573. doi: 10.2307/2669264.

Hobbs, Renee. 2004. "A Review of School-Based Initiatives in Media Literacy Education." American Behavioral Scientist 48 (1):42-59. doi: 10.1177/0002764204267250.

Hobbs, Renee. 2011. "The State of Media Literacy: A Response to Potter." Journal of Broadcasting \& Electronic Media 55(3) 419-430. doi:10.1080/08838151.

Hobbs, Renee, and Richard Frost. 2001. "Measuring the Acquisition of Media Literacy Skills: An Empirical Investigation." International Communication Association, Washington, D.C., May.

Hofschire, Linda J., and Bradley S. Greenberg. 2002. "Media's Impact on Adolescents' Body Dissatisfaction." In Sexual Teens, Sexual Media: Investigating Media's Influence on Adolescent Sexuality, edited by Jane D. Brown, Jeanne R. Steele and Kim Walsh-Childers, 125-149. Mahwah, NJ: Lawrence Erlbaum.

Hurley, Ryan J., Jakob J. Jensen, Andrew Weaver, and Travis Dixon. 2015. "Viewer Ethnicity Matters: Black Crime in TV News and Its Impact on Decisions Regarding Public Policy." Journal of Social Issues 71 (1):155-170. doi: 10.1111/josi.12102.

Irving, Lori M., and Susan R. Berel. 2001. "Comparison of Media-Literacy Programs to Strengthen College Women's Resistance to Media Images." Psychology of Women Quarterly 25 (2):103- 111.

Jeong, Se-Hoon, Hyunyi Cho, and Yoori Hwang. 2012. "Media Literacy Interventions: A Meta-Analytic Review." Journal of Communication 62 (3): 454-472.

Kellner, Douglas, and Jeff Share. 2005. "Toward Critical Media Literacy: Core Concepts, Debates, Organizations, and Policy." Discourse: Studies in the Cultural Politics of Education. 26 (3); 369-386.

Kilbourne, Jean. 2003. "The More You Subtract, The More You Add." In Gender, Race, and Class in Media, edited by Gail Dines and Jean M. Humez. Thousand Oaks, CA: Sage Publications, Inc.

Lavin, Melissa A., and Thomas F. Cash. 2001. "Effects of Exposure to Information About Appearance Stereotyping and Discrimination on Women's Body Images." International Journal of Eating Disorders 29 (1):51-58.

Levine, Michael P., and Kristen Harrison. 2009. "Effects of Media on Eating Disorders and Body Image." In Media Effects: Advances in Theory and Research, edited by James Bryant and Mary Beth Oliver, 490-515. New York, NY: Routledge.

Lewis, Justin, and Sut Jhally. 1998. "The Struggle Over Media Literacy." Journal of Communication 48 (1):109-120.

Masterman, Len. 1985. Teaching the Media. London: Comedia.

Masterman, Len. 2001. "The Theoretical Foundations of Media Education Programs."

In Media Literacy in the Information Age: Current Perspectives, edited by Robert Kubey, 15-68. New Brunswick, NJ: Transaction Publishers. 
Owusu, Susan. 2010. "Using Media Literacy to Combat Racism." Youth Media Reporter 4 (1):15-18.

Piette, Jacques, and Luc Giroux. 2001. "The Theoretical Foundations of Media Education Programs." In Media literacy in the Information Age: Current Perspectives, edited by Robert Kubey, 29-35. New Brunswick, NJ: Transaction Publishers.

Rabak-Wagener, Judith, JoAnn Eickhoff-Shemek, and Lisa Kelly-Vance. 1998. "The Effect of Media Analysis on Attitudes and Behaviors Regarding Body Image Among College Students." Journal of American College Health 47 (1):29-36.

Ridolfi, Danielle R., and Jillion S. Vander Wal. 2008. "Eating Disorders Awareness Week: The Effectiveness of a One-Time Body Image Dissatisfaction Prevention Session." Eating Disorders 16 (5): 428-443.

Scharrer, Erica. 2007. "Closer Than You Think: Bridging the Gap Between Media Effects and Cultural Studies in Media Education Theory and Practice." In Rethinking Media Education: Critical Pedagogy and Identity Politics, edited by Anita Nowak, Sue Abel and Karen Ross. New York, NY: Hampton Press.

Scheibe, Cynthia L. 2004. "A Deeper Sense of Literacy: Curriculum-Driven Approaches to Media Literacy in the K-12 Classroom." American Behavioral Scientist 48 (1):60-68.

Schmidt, Hans C. 2012. "Media Literacy in Secondary and Post-Secondary Education: A Comparison of High School and University-Level Media Literacy Instruction." Journal of Effective Teaching 12 (1): 64-77.

Sholle, David. 1994. "The Theory of Critical Media Pedagogy." Journal of Communication Inquiry 18 (2):8-29. doi: 10.1177/019685999401800202.

Thoman, Elizabeth, and Tessa Jolls. 2004. "Media Literacy a National Priority for a Changing World." American Behavioral Scientist 48 (1):18-29. doi: 10.1177/0002764204267246.

Thoman, Elizabeth, and Tessa Jolls. 2015. Literacy for the 21st century: An Overview \& Orientation Guide to Media Literacy Education. 2nd ed. Malibu, CA: Center for Media Literacy.

Tukachinsky, R., D. Mastro, and M. Yarchi. 2015. "Documenting Portrayals of Race/Ethnicity on Primetime Television over a 20-Year Span and Their Association with National-Level Racial/Ethnic Attitudes." Journal of Social Issues 71 (1):17-38. doi: 10.1111/josi.12094.

Yager, Zali and Jennifer O'Dea. 2008. 'Prevention Programs for Body Image and Eating Disorders on University Campuses: A Review of Large, Controlled Interventions." Health Promotion International 23 (2): 173- 189. doi:10.1093/heapro/dan004.

Watson, R., and L. M. Vaughn. 2006. "Limiting the Effects of the Media on Body Image: Does the Length of a Media Literacy Intervention Make a Difference?" Eating Disorders 14 (5):385-400.

Wood, Julia T. 2011. Gendered Lives: Communication, Gender, and Culture. 9th ed. Boston, MA: Wadsworth. 
A. Bergstrom, M. Flynn \& C. Craig | Journal of Media Literacy Education 2018 10(3), 113 - 131

Table 1

Means and Standard Deviations for Participants

\begin{tabular}{|c|c|c|c|c|c|c|c|c|c|c|c|c|c|c|}
\hline \multirow[b]{3}{*}{ Measure } & \multicolumn{6}{|c|}{ Intervention Group } & \multicolumn{6}{|c|}{ Control Group } & \multirow[b]{2}{*}{ Main Effects } & \multirow[b]{3}{*}{ Delayed Post } \\
\hline & \multicolumn{2}{|c|}{ Baseline } & \multicolumn{2}{|c|}{$\begin{array}{l}\text { Post- } \\
\text { Intervention }\end{array}$} & \multicolumn{2}{|c|}{ Follow-Up } & \multicolumn{2}{|c|}{ Baseline } & \multicolumn{2}{|c|}{$\begin{array}{l}\text { Post- } \\
\text { Intervention }\end{array}$} & \multicolumn{2}{|c|}{ Follow-Up } & & \\
\hline & M & SD & $\bar{M}$ & SD & M & SD & M & SD & $\bar{M}$ & SD & M & SD & Immediate Post & \\
\hline ML1 & 4.04 & 0.81 & 4.33 & 0.67 & 4.3 & 0.76 & 4.09 & 0.83 & 4.16 & 0.81 & 4.17 & 0.83 & & \\
\hline ML2 & 1.55 & 0.86 & 1.59 & 0.93 & 1.67 & 0.93 & 1.54 & 0.88 & 1.47 & 0.79 & 1.5 & 0.83 & & \\
\hline ML3 & 4.09 & 0.84 & 4.46 & 0.73 & 4.35 & 0.73 & 4.12 & 0.85 & 4.12 & 0.87 & 4.21 & 0.84 & $\mathrm{~F}(1,193)=9.41 * *$ & \\
\hline ML4 & 4.45 & 0.76 & 4.48 & 0.78 & 4.68 & 0.51 & 4.45 & 0.75 & 4.32 & 0.81 & 4.28 & 0.82 & & $\begin{array}{l}\mathrm{F}(1,192)= \\
15.26^{* * *}\end{array}$ \\
\hline ML5 & 3.26 & 1.19 & 3.45 & 1.13 & 3.37 & 1.23 & 3.07 & 1.02 & 3.4 & 1.15 & 3.58 & 1.17 & & \\
\hline ML6 & 4.33 & 0.75 & 4.45 & 0.67 & 4.47 & 0.67 & 4.26 & 0.84 & 4.14 & 0.91 & 4.19 & 0.83 & $\begin{array}{l}\mathrm{F}(1,195)= \\
7.56^{* *}\end{array}$ & $\begin{array}{l}\mathrm{F}(1,195)= \\
7.24 * *\end{array}$ \\
\hline ML7 & 4.03 & 0.84 & 4.12 & 0.85 & 4.19 & 0.77 & 4.17 & 0.85 & 4.08 & 0.8 & 4.1 & 0.84 & & \\
\hline ML8 & 3.72 & 0.9 & 4.34 & 0.79 & 4.25 & 0.91 & 3.88 & 0.83 & 3.82 & 0.95 & 3.87 & 1.05 & $\begin{array}{l}\mathrm{F}(1,190)= \\
14.03 * * *\end{array}$ & $\begin{array}{l}\mathrm{F}(1,194)= \\
8.27 * *\end{array}$ \\
\hline ML9 & 4.23 & 0.83 & 4.65 & 0.6 & 4.55 & 0.65 & 4.26 & 0.84 & 4.36 & 0.8 & 4.23 & 0.86 & $\begin{array}{l}\mathrm{F}(1,191)= \\
7.97 * *\end{array}$ & $\begin{array}{l}\mathrm{F}(1,194)= \\
7.29^{* *}\end{array}$ \\
\hline ML10 & 3.89 & 1.02 & 4.36 & 0.84 & 4.23 & 0.82 & 3.88 & 0.95 & 3.81 & 1.07 & 3.86 & 1.03 & $\begin{array}{l}\mathrm{F}(1,195)= \\
14.63 * * *\end{array}$ & $\begin{array}{l}\mathrm{F}(1,194)= \\
8.07 * *\end{array}$ \\
\hline
\end{tabular}

$* \mathrm{p}<.05 . * * \mathrm{p}<.01 . * * * \mathrm{p}<.001$ 
Table 2

Means and Standard Deviations for Intervention Group by Gender

\begin{tabular}{|c|c|c|c|c|c|c|c|c|c|c|c|c|c|c|}
\hline \multirow[b]{3}{*}{ Measure } & \multicolumn{6}{|l|}{ Men } & \multicolumn{6}{|c|}{ Women } & \multirow[b]{2}{*}{ Main Effects } & \multirow[b]{3}{*}{ Delayed Post } \\
\hline & \multicolumn{2}{|c|}{ Baseline } & \multicolumn{2}{|c|}{$\begin{array}{l}\text { Post- } \\
\text { Intervention }\end{array}$} & \multicolumn{2}{|c|}{ Follow-Up } & \multicolumn{2}{|c|}{$\underline{\text { Baseline }}$} & \multicolumn{2}{|c|}{$\begin{array}{l}\text { Post- } \\
\text { Intervention }\end{array}$} & \multicolumn{2}{|c|}{ Follow-Up } & & \\
\hline & $\mathrm{M}$ & SD & M & SD & M & SD & $\mathrm{M}$ & SD & M & $\mathrm{SD}$ & $\mathrm{M}$ & SD & $\begin{array}{l}\text { Immediate } \\
\text { Post }\end{array}$ & \\
\hline ML1 & 3.98 & 0.92 & 4.24 & 0.645 & 4.04 & 0.83 & 4.09 & 0.73 & 4.37 & 0.69 & 4.46 & 0.66 & & \\
\hline ML2 & 1.72 & 0.91 & 1.6 & 0.84 & 2 & 1.09 & 1.45 & 0.82 & 1.6 & 0.99 & 1.47 & 0.76 & & $\mathrm{~F}(1,109)=9.49 * *$ \\
\hline ML3 & 3.93 & 0.88 & 4.29 & 0.84 & 3.98 & 0.82 & 4.18 & 0.8 & 4.56 & 0.64 & 4.58 & 0.56 & & $\begin{array}{l}\mathrm{F}(1,109)= \\
23.91 * * *\end{array}$ \\
\hline ML4 & 4.41 & 0.77 & 4.59 & 0.81 & 4.49 & 0.6 & 4.47 & 0.75 & 4.41 & 0.76 & 4.8 & 0.4 & & $\mathrm{~F}(1,107)=10.35^{* *}$ \\
\hline ML5 & 3.07 & 1.29 & 3.11 & 1.21 & 2.84 & 1.19 & 3.36 & 1.11 & 3.66 & 1.01 & 3.7 & 1.13 & $\begin{array}{l}\mathrm{F}(1,111)= \\
6.54^{*}\end{array}$ & $\begin{array}{l}\mathrm{F}(1,111)= \\
15.28^{* * *}\end{array}$ \\
\hline ML6 & 4.27 & 0.81 & 4.33 & 0.67 & 4.18 & 0.72 & 4.36 & 0.72 & 4.52 & 0.66 & 4.67 & 0.56 & & $\begin{array}{l}\mathrm{F}(1,110)= \\
16.66^{* * *}\end{array}$ \\
\hline ML7 & 4.09 & 0.95 & 4.02 & 0.81 & 4.09 & 0.82 & 3.97 & 0.76 & 4.18 & 0.88 & 4.24 & 0.73 & & \\
\hline ML8 & 3.43 & 0.97 & 4.05 & 0.85 & 3.81 & 0.94 & 3.89 & 0.8 & 4.52 & 0.69 & 4.53 & 0.77 & & \\
\hline ML9 & 4.07 & 0.8 & 4.44 & 0.73 & 4.28 & 0.77 & 4.33 & 0.84 & 4.79 & 0.45 & 4.73 & 0.48 & & \\
\hline ML10 & 3.68 & 0.96 & 4.25 & 0.87 & 4.07 & 0.7 & 4.01 & 1.04 & 4.42 & 0.82 & 4.33 & 0.88 & & \\
\hline
\end{tabular}


Table 3

Means and Standard Deviations for Intervention Group by Race

\begin{tabular}{|c|c|c|c|c|c|c|c|c|c|c|c|c|c|c|}
\hline \multirow[b]{3}{*}{ Measure } & \multicolumn{6}{|c|}{ White } & \multicolumn{6}{|c|}{ Non-White } & & \\
\hline & \multicolumn{2}{|c|}{$\underline{\text { Baseline }}$} & \multicolumn{2}{|c|}{$\begin{array}{l}\text { Post- } \\
\text { Intervention }\end{array}$} & \multicolumn{2}{|c|}{ Follow-Up } & \multicolumn{2}{|c|}{$\underline{\text { Baseline }}$} & \multicolumn{2}{|c|}{$\begin{array}{l}\text { Post- } \\
\text { Intervention }\end{array}$} & \multicolumn{2}{|c|}{ Follow-Up } & \multicolumn{2}{|c|}{$\underline{\text { Main Effects }}$} \\
\hline & M & SD & $\mathrm{M}$ & $\mathrm{SD}$ & $\mathrm{M}$ & $\mathrm{SD}$ & M & SD & $\mathrm{M}$ & $\mathrm{SD}$ & $\mathrm{M}$ & $\mathrm{SD}$ & $\begin{array}{l}\text { Im } \\
\text { med } \\
\text { iate } \\
\text { Post }\end{array}$ & Delayed Post \\
\hline ML1 & 3.95 & 0.78 & 4.27 & 0.66 & 4.23 & 0.72 & 4.26 & 0.85 & 4.43 & 0.7 & 4.43 & 0.82 & & \\
\hline ML2 & 1.56 & 0.82 & 1.55 & 0.91 & 1.59 & 0.81 & 1.55 & 0.96 & 1.71 & 0.97 & 1.87 & 1.15 & & \\
\hline ML3 & 4.07 & 0.81 & 4.41 & 0.74 & 4.36 & 0.7 & 4.12 & 0.91 & 4.56 & 0.71 & 4.32 & 0.81 & & \\
\hline ML4 & 4.44 & 0.71 & 4.4 & 0.83 & 4.67 & 0.53 & 4.46 & 0.85 & 4.63 & 0.65 & 4.71 & 0.46 & & \\
\hline ML5 & 3.28 & 1.13 & 3.43 & 1.08 & 3.39 & 1.14 & 3.17 & 1.32 & 3.44 & 1.23 & 3.28 & 1.39 & & \\
\hline ML6 & 4.22 & 0.74 & 4.38 & 0.67 & 4.43 & 0.66 & 4.54 & 0.74 & 4.57 & 0.66 & 4.54 & 0.7 & & \\
\hline ML7 & 3.95 & 0.87 & 4.12 & 0.82 & 4.15 & 0.8 & 4.17 & 0.78 & 4.11 & 0.92 & 4.25 & 0.69 & & \\
\hline ML8 & 3.53 & 0.87 & 4.33 & 0.79 & 4.1 & 0.98 & 4.09 & 0.83 & 4.32 & 0.81 & 4.56 & 0.66 & & $\mathrm{~F}(1,109)=5.07^{*}$ \\
\hline ML9 & 4.18 & 0.84 & 4.66 & 0.58 & 4.52 & 0.65 & 4.33 & 0.82 & 4.64 & 0.65 & 4.61 & 0.66 & & \\
\hline ML10 & 3.91 & 0.97 & 4.39 & 0.77 & 4.18 & 0.84 & 3.83 & 1.12 & 4.26 & 0.98 & 4.31 & 0.76 & & \\
\hline
\end{tabular}

